\title{
DUAS NOVAS OCORRENCIAS DE ORCHIDACEAE PARA A FLORA BRASILEIRA ${ }^{(1)}$
}

\author{
Manoela Ferreira F. da SILVA ${ }^{(2)}$, João Batista F. da SILVA ${ }^{(3)}$
}

Resumo - Duas espécies de Orchidaceae, Myoxanthus parvilabius (C. Schweinf.) Luer e Trichosalpinx intricata (Lind) Luer, foram registradas pela primeira vez para a flora brasileira, ambas encontradas no município de Santa Izabel do Rio Negro, Amazonas, Brasil.

Palavras-Chave: Biogeografia, Amazonia, Orchidaceae, Myoxanthus parvilabius, Trichosalpinx intricata

\section{Two New Orchid Occurrences for the Brazilian Flora}

Abstract - Two new orchid for the Brazilian flora, Myoxanthus parvilabius (C. Schweinf.) Luer and Trichosalpinx intricata (Lind) Luer, were found in the municipality of Santa Izabel do Rio Negro, Amazonas, Brazil.

Key-words: Biogeography, Amazonia, Orchidaceae, Myoxanthus parvilabius, Trichosalpinx intricata

\section{INTRODUÇÃO}

A familia Orchidaceae é uma das mais ricas em espécies no mundo, apresentando sua maior diversidade nas regiões tropicais. No Brasil, em especial na Amazônia, essa diversidade é muito acentuada, porém, ainda muito mal conhecida.

Alguns estudiosos destacaram $\Rightarrow$ se na orquideologia brasileira em períodos distintos. Para a Amazônia Brasileira, vários trabalhos de cunho regional foram desenvolvidos nas década de 70 e de 80 , por Pedro Ivo Soares Braga, então pesquisador do Instituto Nacional de Pesquisas da Amazônia - INPA. Seus estudos foram direcionados ao ecossistema campina amazônica, em especial à Amazônia Central e Ocidental (Braga 1981;
1982). Porém, para outros tipos de ambientes e para outras áreas da região a flora orquídica continuou sendo pouco estudada, e, portanto, muito mal conhecida. Na duas últimas décadas, através de um inventário intensivo das Orchidaceae, tem sido possivel alcançar áreas amazônicas antes inacessiveis, o que vem ajudando no conhecimento da flora orquidica regional através da coleta de material para estudo nunca ou pouco registrado anteriormente. Destacam-se, como regiões pouco conhecidas, as áreas de fronteiras do Brasil ao norte, com as Guianas e Venezuela, os altos cursos dos rios formadores da bacia amazônica e áreas centrais inacessíveis, como a Serra dos Carajás, cujo acesso só foi possivel com a descoberta de minério

\footnotetext{
'Projeto integrado do $\mathrm{CNPq}$ (Estudo e Conservação de Orquideas na Amazônia Brasileira), Proc. 521148/96-6.

${ }^{2}$ Faculdade de Cièncias Agrárias do Pará - FCAP, Av. Tancredo Neves S/N, 66.077-530; Museu Paraense Emílio Goeldi, Av. Magalhães Barata, 376 - São Braz. 66060-170 - Belèm, PA, Brasil. e-mail: manoela@museu-goeldi.br.

${ }^{3}$ Bolsista de Apoio Técnico do CNPq, Proc. 521148/96-6.
} 
e a implantação de projetos de exploração iniciada na década passada. Dessa maneira, tem sido possível redescobrir espécies, ampliar a distribuição geográfica de outras, descobrir novas ocorrências e descrever novas espécies para a flora brasileira (Silva et al., 1995, Silva \& da Silva, 1997).

Dentre as novas descobertas durante o desenvolvimento do projeto, são aqui apresentados, como novos para a flora brasileira, dois táxons: um pertencente ao gênero Myoxanthus e o outro ao Trichosalpinx. O gênero Myoxanthus Poepp. \& Endl. pertence ao grupo das Pleurothallides e foi reconhecido como gênero independente por alguns autores e como sinônimo de Pleurothallis por outros (Luer, 1986). Um estudo detalhado de todo o grupo vem sendo realizado pelo especialista Carlyle A. Luer, na série Icones Pleurothallidinarum, Sistematics of Pleurothallis (Orchidaceae), do Missouri Botanical Garden. Anteriormente, o mesmo autor publicou uma reavaliação do gênero Myoxanthus (Luer, 1982), reconhecendo 47 espécies de em três subgêneros. A grande maioria das espécies está distribuida desde o México, toda a América Central e ao Norte da América do Sul. Para o Brasil eram conhecidas somente três espécies, $M$. exasperatus (Lindley) Luer, que ocorre no centro-oeste e sudeste brasileiro, $M$. lonchophyllus (Barb. Rodr.) Luer, com ocorrência na região central do Brasil, e $M$. aspasicensis (Reichb.f.) Luer, registrada para o estado do Amazonas. Myoxanthus parvilabius (C. Schweinf.) Luer era conhecida somente para a Guiana, Suriname, Venezuela e Equador. No momento, a espécie foi registrada ocorrendo em território brasileiro.

O gênero Trichosalpinx Luer foi segregado de Pleurothallis $\mathrm{R}$. Br., Sec. Lepanthiformes (Lind.) Cogn., como o gênero anteriormente tratado, pelo especialista do grupo, por apresentar diferenças significativas na coluna (Luer, 1984). Neste trabalho o autor separou as espécies que se enquadravam no, então, novo gênero, perfazendo, aproximadamente, 90 espécies, resultantes das novas combinações. Desta forma, Pleurothallis intricata Lindl. passou a pertencer ao novo gênero Trichosalpinx. Apesar deste gênero possuir um número elevado de espécies, sua ocorrência na flora amazônica é quase que totalmente desconhecida. A espécie aqui apresentada, Trichosalpinx intricata (Lindl.) Luer, até recentemente era conhecida apenas para a Colômbia e Venezuela e agora foi registrada para o Brasil.

\section{RESULTADOS}

Myoxanthus parvilabius (C. Schweinf.) Luer, Selbyana 7: 49, 1982. (Fig. 1)

Epífita com caules robustos, eretos, proliferos, $70 \mathrm{~cm}$ compr., 0,2 $\mathrm{cm}$ diâm.; folhas eretas, coriáceas, elipticas, $5-10 \mathrm{~cm}$ compr., $1-1,5 \mathrm{~cm}$ larg.; inflorescência em fascículo, flores com sépala dorsal oblongo- 


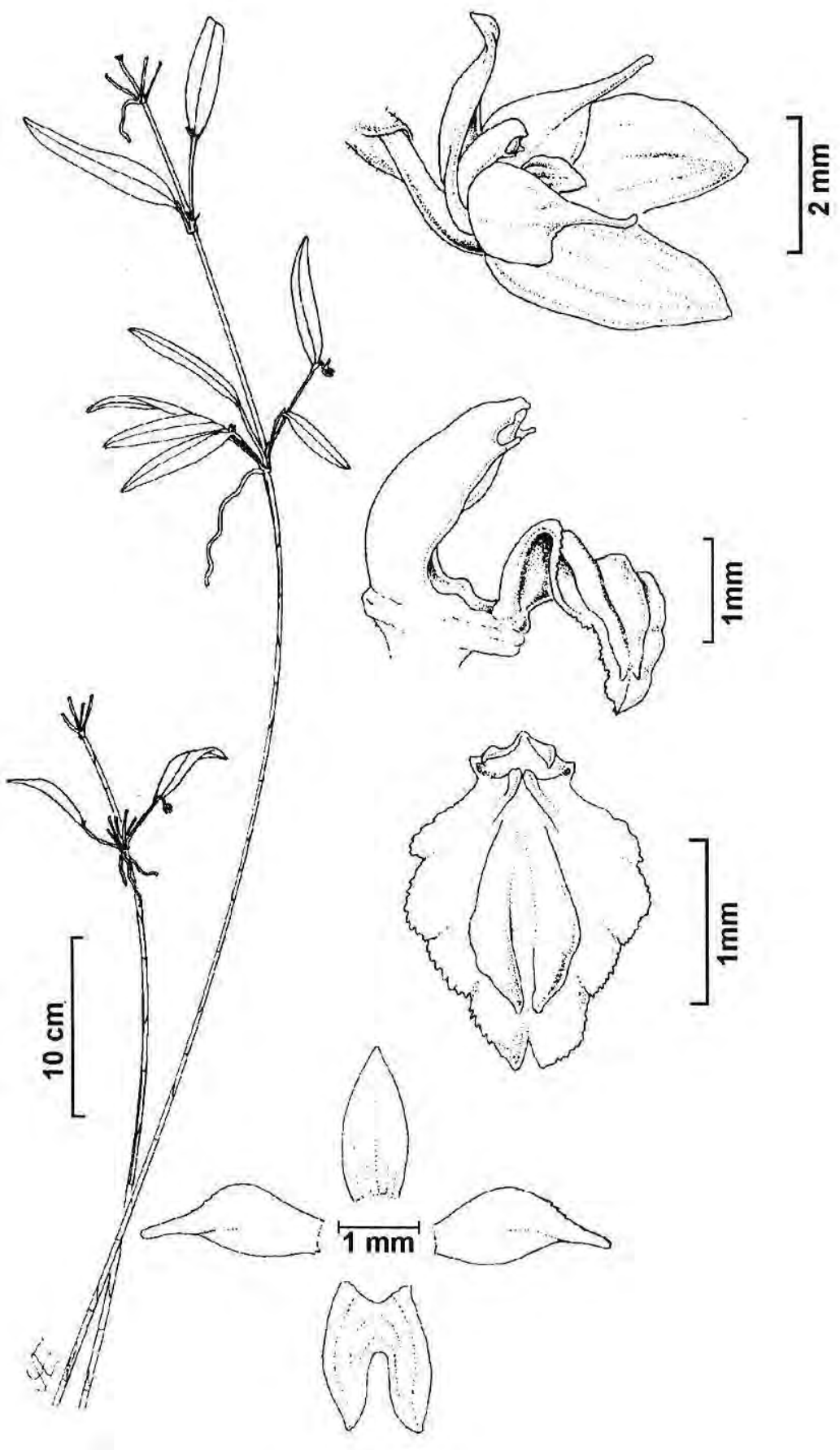

Figura 1. Myoxanthus parvilabius ( C. Schweinf.) Luer

Duas novas ocorrências de Orchidaceae para a ...

183 


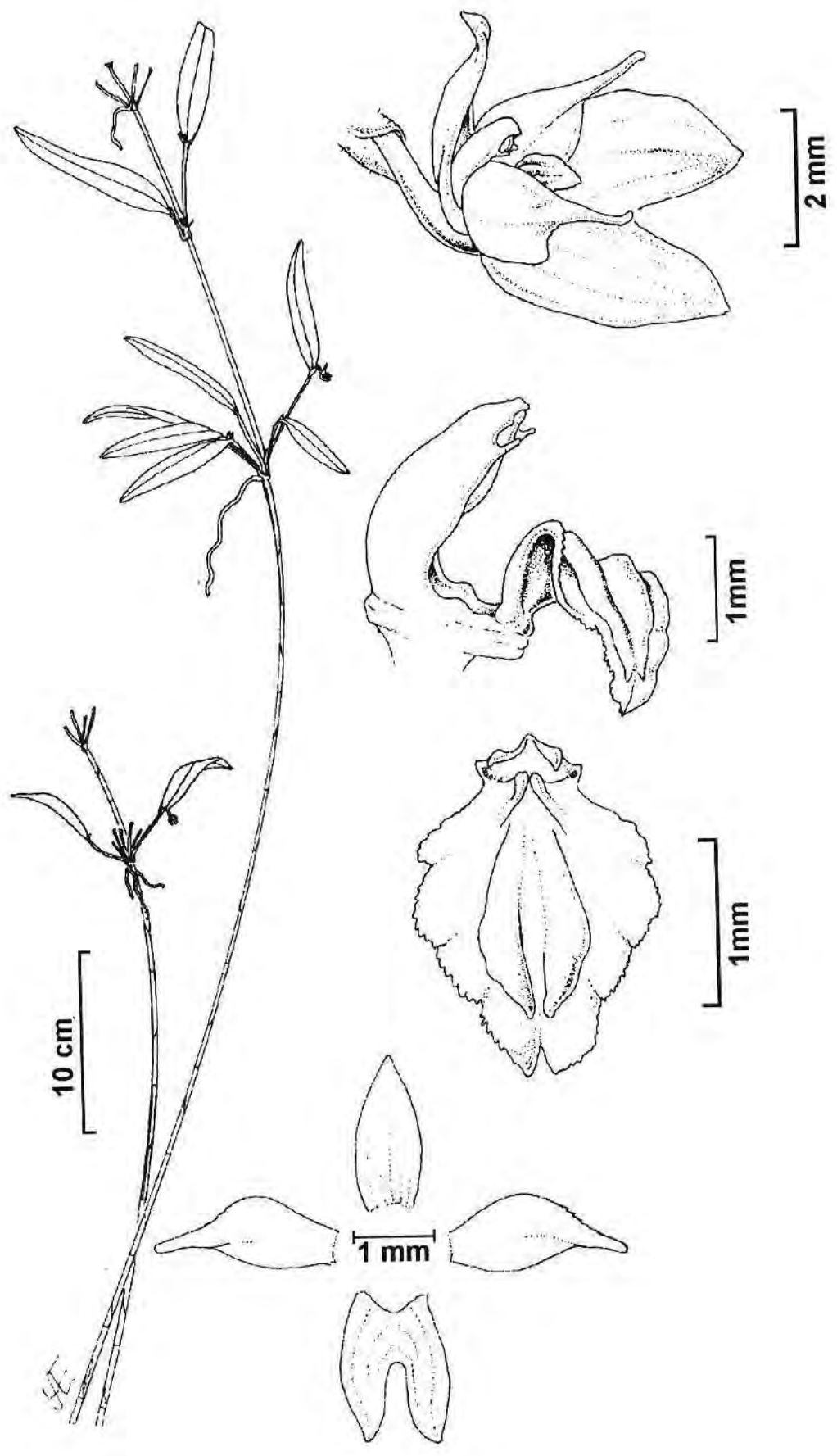

Figura 2. Trichosalpinx intricata (Lindl.) Luer

184

Silva \& Silva 
ovada, ligeiramente acuminada, glabra, $2 \mathrm{~cm}$ compr., $0,8 \mathrm{~cm}$ larg.; as laterais ovadas, apiculadas, obliquas, obtusas, $2 \mathrm{~cm}$ compr., 1,2 cm larg.; pétalas subobovadas, levemente denteadas, 2,1 cm compr., $1 \mathrm{~cm}$ larg.; labelo profundo, grosso, largamente obovado, arqueado, ápice largamente arredondado, margem denticulada; disco com um par de pequenos calos arredondados, na base e abaixo dos calos apresenta um par de lamelas paralelas na região central, com as bases dobradas até o ápice; coluna grossa, robusta, subereta, $2 \mathrm{~mm}$ compr.

Distribuição: América Central, Brasil (AM), Colômbia, Equador, México, Venezuela.

Habitat: Floresta úmida entre 400 e $900 \mathrm{~m}$ de altitude no Pico da Neblina e nas caatingas abertas nas margens do rio Cuiabixi à $400 \mathrm{~m}$ de altitude.

Material examinado: Brasil, Amazonas, município de Santa Izabel do Rio Negro, Serra do Tucano, margem do rio Cuiabixi; J.B.F. da Silva 544. 13/09/95. (MG 149897)

Trichosalpinx intricata (Lindl.) Luer, Phytologia 54(5): 393-398. 1984. (Fig. 2)

Epifita com caules agregados, eretos, invaginantes, unifoliados, $3 \mathrm{~cm}$ compr., $0,1 \mathrm{~cm}$ diâm.; follhas carnosas, oblongo-elipticas, coriáceas, tridenticuladas no ápice, $0,6 \mathrm{~cm}$ compr., 0,2 cm larg.; inflorescência fasciculada, flores com sépalas membranáceas, a dorsal na sua porção basal ovada, depois largamente caudado-atenuada, $0,5 \mathrm{~cm}$ compr., 0,1 cm larg.; as laterais linear-lanceoladas, soldadas na base até a metade, $0,6 \mathrm{~cm}$ compr., $0,1 \mathrm{~cm}$ larg.; pétalas elípticas, obliquas, $0,2 \mathrm{~cm}$ compr., $0,1 \mathrm{~cm}$ larg.; labelo trilobado, aplanado no ápice dos lobos laterais; lobos laterais curtos, eretos, obtusos, lobos intermediário oblongo-ligulados, ápice subtruncado; disco por cima dos lobos laterais, em cada lado com uma lâmina curta, dentiforme; coluna robusta, ligeiramente dilatada até o ápice, 2 mm compr.

Distribuição: Brasil (AM), Colômbia, Venezuela.

Habitat: Faixa superúmida da Serra da Neblina, crescendo entre os musgos e liquens a mais de $2.000 \mathrm{~m}$.

Material examinado: Brasil, Amazonas, municipio de Santa Izabel do Rio Negro, Serra da Neblina (2 a 3 mil metros de altitude). J.B.F. da Silva 468. 15/09/95. (MG 148485).

\section{AGRADECIMENTOS}

Ao Sr. Antônio Elielson Rocha (DBO/MPEG) pelas ilustrações e ao Dr. Ricardo Secco pela constante colaboração na leitura do manuscrito. À Comissão Demarcadora de Limites e à Fundação Botânica Margaret Mee pelo apoio ao trabalho de campo e concessão de bolsa de pesquisa.

\section{Bibliografia Citada}

BRAGA, P.I.S. 1981. Orquideas das Campinas da Amazônia Brasileira. In: Encontro de Orquidófilos e Orquidólogos 1, Rio de Janeiro, 1981, Anais. Rio de Janeiro, Expressão e Cultura, p. 19-43.

BRAGA, P.I.S. 1982. Aspectos Biológicos das Orchidaceae de uma Campina da Amazonia Central. II-Filogeografia das Campinas da Amazonia Brasileira. 
Instituto de Pesquisas da Amazônia/ Fundação Universidade do Amazonas, Manaus. Tese de Doutorado. 305p.

Luer, C.A.1982. A re-evaluation of the genus Myoxanthus. Selbyana, 7:34 - 54.

Luer, C.A. 1984. Tricosalpinx, a new genus in the Pleurothallidinae. Phytologia, 54(5):393-398.

Luer, C.A. 1986. Icones Pleurothallidinarum I. Systematics of the Pleurothallidinae. Monogr. Syst. Bot. Missouri Bot. Gard., 15:35-39.

Silva, M.F.F.; Sila, J.B.F.; Rocha, A.E.S; Oliveira, F.P.M; Silva, M. F. ; Queiroz, O.H.A. 1995. Inventário da família Orchidaceae na Amazônia Brasileira. Parte I. Acta Bot. Bras., 9(1):163-175.

Silva, M.F.F.; Silva, J.B.F. 1997. Novas ocorrências de Orchidaceae para o Brasil. Bol. Mus. Para. Emilio Goeldi, sér: Bot., 13(1):69-79. 